Instituto Internacional de Investigación y Desarrollo Tecnológico Educativo INDTEC, C.A.

DOI: https://doi.org/10.29394/Scientific.issn.2542-2987.2018.3.7.20.394-414

OAI-PMH: http://www.indteca.com/ojs/index.php/Revista Scientific/oai

\title{
La Historia desde la Imagen Poética
}

\author{
Autora: Rina Desireé Colina Matos \\ Universidad Nacional Experimental "Rafael María Baralt", UNERMB \\ desicolina1203@gmail.com \\ Trujillo, Venezuela
}

\section{Resumen}

El presente ensayo procura explorar los vínculos existentes entre el discurso de la Literatura y el de la Historia; dentro de este contexto, se busca plantear a partir de la imagen poética reflejada en los textos: Canto General de Pablo Neruda (1950) y Santiago de León de Caracas de Ramón Palomares (1967), una lectura plurivisionaria que resulta ser una opción para acercarnos a la historia de una forma distinta a la presentada en los programas educativos. Partiendo de la idea que la Literatura es reveladora de sentidos, descubre la presencia del Otro. En síntesis, se plantea el análisis de los textos propuestos anteriormente con el objeto de demostrar el discurso alternativo de la Historia que presentan estos poetas, donde se establece una relación dialógica entre la Literatura y la Historia. Finalmente, se pretende que estas reflexiones puedan ser un aporte para el proceso de formación de los estudiantes de la Escuela Venezolana.

Palabras clave: literatura; historia; poesía; discurso. 


\title{
The History from the Poetic Image
}

\begin{abstract}
This essay seeks to explore the links between Literature and History discourse; whithin this context, it seeks to raise from the poetic image reflected in the texts: General Song from Pablo Neruda (1950) and Santiago de León de Caracas from Ramón Palomares (1967), a multi-vision reading that turns out to be an option to get closer to history in a different way than the presented in educational programs. Starting from the idea that Literature is a revealing of senses, it discovers the presence of the Other. In synthesis, it raises the analysis of the texts previously proposed with the object of demonstrating the alternative speech of History presented by these poets, where a dialogical relationship between Literature and History is established. Finally, it is intented that these reflections may be a contribution to the training process of the students of the Venezuelan School.
\end{abstract}

Keywords: literature; history; poetry; speeches. 


\section{Introducción}

Siempre las hazañas del hombre, en su largo o corto transitar por la vida, son objeto de interés para muchas mentes; especialistas dedican su labor al estudio riguroso de esos hechos. En este proceso de reconstrucción de los acontecimientos relevantes o no del ser humano, se ven involucrados una serie de aspectos que mezclados y trabajados desde la memoria vierten una gran responsabilidad sobre la historia que se imparte en las instituciones educativas: motivo este que influye directamente en la formación cultural del estudiante. Las letras, las palabras y los discursos, adquieren gran importancia y amparo al gozar de credibilidad ofrecidas por las élites que así lo convienen.

La Literatura como concepto que designa un acto peculiar de la comunicación humana y que podría definirse como el arte de escribir, escritura, alfabeto, gramática, conjunto de obras literarias, que son creaciones artísticas expresadas con palabras, aun cuando no se hayan escrito, sino propagado boca a boca; permite plasmar o transmitir por escrito y oralmente la cultura viva y autóctona, aspectos que también son estudiados y dados a conocer por la Historia en general y que yacen forjados e inertes en la Historia unívoca programadas generalmente en los planes de estudio que los docentes han insistido en impartir o enseñar. Estos hechos del pasado del hombre, en ocasiones son interpretados por los docentes considerando que la información de que disponen es completa, totalmente correcta; sin evidenciar que éstas pueden estar retenidas o ser erróneas, fragmentarias o prácticamente ininteligibles tras un gran intervalo temporal que haya causado grandes cambios culturales o lingüísticos. Por tanto, el maestro ha de enjuiciar críticamente los testimonios que maneja y por ende requerir de un cuidadoso tratamiento.

Como ser cultural, cada individuo tiene una gran necesidad de evocar y escudriñar en su pasado, y saber en un sentido más amplio su Historia, como esa totalidad de sucesos humanos acaecidos en un espacio geográfico 
temporal determinado; éstos pueden conocerse mediante cualesquiera que sean las fuentes documentales que ciertamente el historiador utiliza poniendo de esta manera en contacto a la Historia con la Literatura, es por ello que éstas se cruzan para dar así un cuadro anecdótico y simbólico del individuo y el colectivo, que acciona en una época, en un tiempo que transcurre y logra inmortalizarse por su carácter convincente y revelador.

En la educación del individuo se divisan ambas caras de la moneda: la cruda o fuerte realidad y la ornamenta histórica escolarizada disfrazada de verdades, alejada en gran parte del contexto realista de los hechos. El intérprete de cada una de estas visiones es responsable de lo que de un momento en adelante se sacará a la luz pública y complementará la vida de los individuos que luchan por una educación digna y confiable; en otras palabras, es el docente quien tiene en sus manos el propagar la epidemia o el entregar un antídoto para el veneno de la falsificación, que viene extendiéndose a lo largo de los años, situación que ha sido compartida y amparada por la escuela venezolana.

En este sentido, las reflexiones que se llevan a cabo tienen la intención de proponer una lectura alternativa de la historia, superadora de la univocidad centralizada de los hechos que en la actualidad se muestran como paradigma en la Escuela Venezolana. Por ello, el propósito fundamental de este ensayo nace a partir de la desconexión parcial, planteada inicialmente entre los conceptos propuestos. En este caso, la poesía se presenta como un ámbito que propicia la producción de otros discursos.

Se pretende analizar ambas manifestaciones del lenguaje con el propósito de lograr establecer la conexión entre ellos y tomarlos como estrategia para el fundamento cognoscitivo y experiencial del estudiante como individuo. Este análisis incluye dos textos de dos escritores latinoamericanos. El primero es un escritor chileno, Pablo Neruda con su libro Canto General (1950a) y el segundo venezolano, Ramón Palomares con su libro Santiago de 
León de Caracas (1967), quienes hacen referencia a la Historia a través de sus poéticas reveladoras.

\section{El Lenguaje, la Lectura y la Escritura}

Toda experiencia posibilita en el ser acceso al conocimiento; por esta razón en la formación de un individuo, participan una serie de aspectos 0 fundamentos, notables para su desarrollo humano y cognitivo; estos constituyen amplios factores que se involucran directamente en el proceso evolutivo del hombre como ser trascendente. Por lo general, las experiencias del hombre registran su memoria desde el lenguaje, la lectura y la escritura; aspectos que ayudan en su desarrollo intelectual y por ende cultural. Motivos que despiertan nuestra inquietud, incentivándonos al estudio de dichos aspectos, preguntándonos si verdaderamente elevan las conciencias de nuestros estudiantes, constituyendo su esencia como ser humano, apuntando especialmente a los involucrados en nuestra escuela.

Valverde (2014a), considera respecto a la lectura y escritura:

...No se puede perder de vista, que a través del fascinante mundo de la lectura, se puede conocer mundos, poco imaginados, quizás irreales, poco existentes, no obstante al representarlos en la escritura, su desgarramiento, ese desangre de sentimientos, pensamientos esas vigilias que liberan la fatiga, el disgusto, lo inquietante que fluyen desde adentro conllevan a reflejar pensar e interpretar el mundo. De ahí, que la lectura se convierta en la elaboración escrita de diferentes textos, enmarcados en contextos infinitos como punto de partida y de llegada a la vez. Indiscutiblemente el mundo que nos rodea necesita ser leído, para reconstruirlo a partir de la escritura (pág. 73).

La lectura juega un papel muy importante en el proceso evolutivo del hombre por cuanto le permite "ver más allá" de lo que se encuentra al alcance de su vista, formándolo a nivel cognoscitivo, elevando su espíritu, humanizando sus sentidos. Como acto continuo en el proceso de formación, 
la lectura conduce al hombre al encuentro con las múltiples realidades, acercándolo al disfrute, tocando a fondo sus sentidos para ampliarlos ante cualquier situación. El acto de lectura implica una experiencia determinante dentro del proceso de aprendizaje, le permite al individuo interactuar con su lenguaje, haciendo al hombre un ser que juega, crea o destruye con su imaginación, al tener contacto con los textos; contacto físico significativo que lo acerca al mundo, considerando al texto como lectura del mismo o simplemente lo aparta de su realidad para llevarlo a otras dimensiones.

En este sentido, Valverde (2014b), considera que:

...la lectura se convierte en una gama de alienaciones, como un eco de inquietudes, sensaciones un sin fin de intimidades que de una u otra manera desembocan en la difícil tarea de escribir, como un cuentagotas que de a poco finalmente termina por estructurarse en material para ser leído y consumido por la sociedad (págs. 73-74).

Palabra y silencio constituyen a la lectura como acto sublime que eleva el sentido de quien lo vivifica, aceptando las voces de quienes poseen oportunidades verdaderas, es decir, de aquellos que se liberan ante el sentido de la imaginación. Abriéndonos a diversidad de culturas que bordean el centro de nuestra atracción, facilitándonos el desplazamiento a través de ellas, todo va a depender de nuestra interpretación. Leer es conocer el mundo, y el mundo es ese gran libro que se abre ante nuestros ojos para mostrarse como hombre o mujer, como sujeto u objeto, como norte o como sur; todo es una posibilidad que se abre o se cierra, según su intérprete. Así, "la lectura es un camino de ida y regreso; del texto a la realidad y de esta al texto". Valverde (2014c, pág. 75). A través de la lectura el hombre adquiere conciencia de sí mismo, de su desarrollo humano, del contexto que lo rodea y de los componentes que sustentan dicho contexto; en este proceso de formación, el hombre establece un contacto con el lenguaje, con palabras creadoras de discursos, discursos que tocan su sensibilidad, reflejándolas de manera sublime de acuerdo con su 
estado intrínseco.

El lenguaje también registra la memoria de cada persona, es un aspecto que contribuye en su desarrollo intelectual y cultural como se dijo en líneas anteriores, el lenguaje es "una necesidad social de comunicación entre los individuos" Valverde (2014d, pág. 75). Entonces, la poesía registra las memorias de cada individuo, es una forma de lenguaje que le permite al hombre viajar y trasladarse a mirar su propia esencia bien sea para complementarla o para cuestionarla, es decir, un acercamiento consigo mismo y con el mundo en general, también implica una manera especial de descubrir el enigma de las cosas y de gozar con la magia y el poder de las palabras; es reveladora de la razón, haciéndose subversiva ante la esperanza de lo sensato, Paz (1956a, pág. 13), "La poesía es conocimiento, salvación, poder, abandono. Operación capaz de cambiar el mundo, la actividad poética es revolucionaria por naturaleza; ejercicio espiritual, es un método de liberación interior; la poesía revela este mundo, crea otro".

La poesía admite el establecer una revuelta de sentidos, en la cual la persona manifiesta su esencia, revelándose contra la razón, declarando su verdadera identidad, trasladando su pensamiento a dimensiones profundas, pensamiento tal que amenaza los cánones de la sociedad: rompiendo las leyes o normas establecidas por la misma, estimulando los cambios y la creatividad del individuo, que la mayoría de las veces ha sido coartada, especialmente en la escuela donde el niño desea expresar su mundo interno, pero este ha sido limitado por la pedagogía y los programas curriculares educativos.

\section{Historia y Poesía, una larga y compleja relación.}

La Historia que se imparte en las escuelas (también la Literatura), está regida por normas que tienden a convertir la enseñanza de ésta en limitante para la formación del educando, tal como lo plantean Acevedo, Arista, Carretero, Lima, Miralles, Prats y Santacana (2011:18), "la historia como 
materia escolar, no debe concebirse como un cuerpo de conocimientos acabados, sino como una aproximación al conocimiento en construcción". La historia escolar solo llega a revelarle al estudiante una parte de los hechos ocurridos en el pasado, mientras que la poesía, dada la naturaleza de su discurso, puede acceder al pasado de una manera más libre, cuestión que permite pensar que su relación con el pasado puede resultar una experiencia mucho más atractiva y estéticamente significativa en el contexto escolar.

La Historia, como disciplina científica, pretende controlar las condiciones subjetivas de quien la escribe; mientras que la Literatura delata sin vacilaciones las intenciones del ser, produciéndose así una ruptura entre la concepción poética y la concepción histórica, planteamiento que realiza Siwka (1982a), la autora establece la separación casi hostil de los campos respectivos del escritor y el historiador, producido por el establecimiento 0 consolidación de la historia como ciencia, al ser transformada, interpretada e insertada en la sociedad (escuela) como un discurso teórico que trata de beneficiarse de otras ciencias.

Relacionando el discurso literario con el discurso histórico, se plantea la producción de un discurso que hable desde varias perspectivas, que cubra las necesidades y expectativas del sujeto en formación, y que a su vez destaque los hechos acontecidos en un espacio geográfico-temporal determinante para el ser humano en la constitución de su cultura, Siwka (1982b):

Sin duda la Literatura y la Historia, son más impresionantes, más llamativas, más leídas y sus efectos sociales y políticos son de mayor relevancia cuando evocan los episodios sociales de los pueblos y cuando exponen a la luz, el eterno humano (pág. 23).

Existe una relación dialógica que pretende establecerse entre el universo de la Literatura y el universo de la Historia (mediante sus discursos), 
estos han estado muy por debajo de la mirada de los estudiosos, puesto que, tanto uno como el otro ha tratado de abarcarse de manera trivial y por separado. El discurso literario se ha estudiado, como ese arte que embellece y da color a ciertos hechos, pero no nos hemos dado cuenta de que la cultura que conforma al hombre tiene que ver con la palabra y con el tiempo, tal como lo dice Hernández (1998), la palabra (poesía) y tiempo (Historia) afianzan al individuo en un entorno representativo. Entonces, no es nuevo para nosotros que la esencia misma del hombre está en sus vivencias, sus hazañas, en lo que nombra y en lo que imagina.

Sin embargo, en la evolución de estos discursos se genera una ruptura al pretender, generalmente la historia escolarizada, estudiar al hombre únicamente en su contexto social; considerando a la sociedad como un cuerpo orgánico sometido por leyes, procesos, cambios y explicaciones. Este divorcio entre lo literario y lo histórico se produce a partir de las diferencias que se han planteado anteriormente entre ambos discursos. La Historia no puede establecerse como oposición a la Literatura, puesto que el historiador acude necesariamente la Literatura, como soporte de apoyo a sus consideraciones.

Se concibe el arte como la expresión inmediata del sentimiento y, por lo tanto, de la concreta individualidad del artista. El sentimiento define a los individuos, mientras que la razón es común a todos los hombres; por esto la Literatura y la razón son representantes de la Poesía e Historia. La Literatura, es el conocimiento del mundo a través de sus lenguajes, altera y amplía la razón dominadora de la ciencia y pone al hombre, sobre sus realidades, al frente de las distintas lógicas enriquecedoras del sentido. Mientras que la historia escolar construye un discurso monovalente desde el hecho y el documento. La Literatura amplifica su cobertura en el mundo de los sentidos. Esto indica cómo debe ser diferente la pedagogía y la didáctica para la enseñanza de ambos saberes y no pueden ser orientadas de la misma manera. 
Se considera que a partir de la escritura, las dos formas que tiene el hombre para acercarse a su pasado histórico son el discurso literario y el discurso histórico; ambos de carácter narrativo, sólo que uno: el discurso histórico, relata los hechos en un sentido historiográfico, es decir, analiza e interpreta los documentos y fuentes históricas para elaborar la narración histórica, y el otro, el discurso literario, reconstruye y replantea ese discurso historiográfico, formulando así sentidos alternativos para asumir la Historia. En este sentido, hay que acentuar no sólo los aspectos que diferencian al discurso literario del discurso histórico, sino también se busca enlazar la Literatura e Historia, a través de las posibles relaciones de identidad que caracterizan estas dos formas narrativas.

Se infiere de estos planteamientos que esta correspondencia entre los discursos en cuestión, se establecen en el acto de narrar; la temporalidad y la narración en la Literatura y en la Historia, establecen una relación de concordancia, de correlación; puesto que el tiempo es ordenación de la subsistencia o coexistencia de los individuos a lo largo de un período determinado (si de tiempo cronológico se trata); la temporalidad se funda como estilo, como ideal de vida que accede precisamente al lenguaje a través de la narratividad, (encontrada también en la Historia), que tiene como último referente dicha temporalidad y se desdobla en una dimensión cronológica y en otra humana (Literatura) también o sobre todo en la Historia.

\section{La Imagen Poética como fuente Lectora de la Historia.}

El poeta reescribe al cosmos desde su inspiración, lo reproduce o juega con éste desde sus creaciones poéticas, donde la palabra, el lenguaje, la escritura misma y la Historia, se cruzan como visiones de un propósito humano en la sociedad; en tal sentido, en este apartado se busca plasmar la peregrinación que los poetas en cuestión hacen por la Historia desde la Imagen Poética, de tal manera que permitan afirmar que la Imagen Poética si 
puede establecerse como fuente lectora de la Historia; por supuesto desde una perspectiva pedagógica. Los textos de Neruda y Palomares presentan una encarnación de voces, de sujetos históricos materializados por el documento e interpretados de otra manera por la Imagen Poética o en este caso particular, voces acalladas que dialogan de manera reiterada y antagónica con sus opresores.

Los autores de Canto General y Santiago de León de Caracas, responden de manera reflexiva y distinta, a un conflicto de su tiempo, avivando al fuego de sus palabras y poniendo sus textos de evidencia para suscitar encuentros dialógicos de sujetos históricos, diálogos que, aunque antagónicos, permiten la mirada múltiple de acontecimientos que revierten el acervo cultural de nuestros pueblos. En esta interlocución de clamores, florece una apología que coloca en evidencia dichos discursos, alegatos que en nombre del poder han profanado sujetos históricos.

En atención a los aspectos ya señalados, comienza la disertación sobre las obras de estos poetas partiendo de Pablo Neruda, en su Canto General, desata su ira mezclada con el dolor y la impotencia para plasmar con sus más acertadas palabras, las injusticias cometidas por los conquistadores de América y muy en específico por su Chile querido. La Imagen Poética trabajada concienzudamente por Neruda, nos muestra modos diferentes de ver la Historia, logrando con ello la recreación de un pasado oculto que merece ser descubierto. Es preciso destacar que el poeta en general escribe acerca de cosas que ve, pero en este caso particular, Neruda es víctima de muchos atropellos, siendo el mayor de ellos el exilio de su patria natal.

La Historia de América es interpretada por Neruda con seriedad y rebelión, al ser uno de los mayores opositores de las jugarretas que el poder acostumbra hacer. La memoria de los pueblos es trasladada por el poeta aun contexto más amplio y profundo, lo inamovible falsea su terreno dejando a la luz aquello de lo cual no se habló, porque no era conveniente. Frente al empuje 
popular se levantan resistencias y coaliciones de fuerzas que usan todos los medios: la represión brutal, la dictadura ominosa y antinacional con su cortejo de negación de libertades y de derechos, aun los más elementales, para impedir transformaciones que alteren los sistemas de dominación imperantes, que conduzcan a estructuras más evolucionadas, a formas de convivencia más humanas y dignas, y a la verdadera independencia de los países latinoamericanos.

Realidades de tanta envergadura, que menoscaban la gran patria americana, que asfixiaban al hombre estrechando sus horizontes y mutilando gravemente su propia humanidad, tenían necesariamente que impactar -y de múltiples maneras- una conciencia tan lúcida y siempre despierta como la de Neruda. De ahí que ellas sean evocadas una y otra vez en Canto General, hasta construir el hilo central de su textura, Neruda (1950b, pág. 336): "Me duele en ti mi pueblo, toda mi patria americana, todo lo que han roído tus huesos, dejándote ceñida por la espuma, como miserable diosa despedazada". Dolía a su humanismo integral y sin reservas, un estado de cosas alienantes y deteriorantes de los pueblos que componían su amada patria americana. Laceraba profundamente su espíritu americanista sin límites, la presencia devoradora del imperialismo, Neruda (1950c, pág. 199): "Llegó el dólar de dientes agresivos, a morder territorio, en la garganta pastoril de América."

Con Canto General, Neruda realiza un acto de autovaloración definitivo y definitorio. Él se sitúa en una perspectiva que abre nuevos senderos a su obra. Ahora parte del hombre -pero no del hombre abstracto e individual, sino del ser social concreto y actuante- y de la tierra -la tierra americana que es fuente de belleza, pero también está ligada dialécticamente al hombre- con lo que sigue, enriqueciéndola y dándole un real contenido histórico-social, la línea inaugurada por los viejos maestros del humanismo renacentista.

Neruda puede trazar entonces en Canto General la marcha o el 
desarrollo continuo de la Historia de América desde los lejanos tiempos precolombinos hasta mediados del siglo XX. Penetra en el recóndito mundo indígena, asciende a Macchu Picchu. Neruda (1950d, pág. 29), dice: "puse la frente entre las olas profundas, descendí como gota entre la paz sulfúrica y, como ciego, regresé al jazmín de la gastada primavera humana".

A partir de allí, el poeta sigue el avance de la Historia. Se detiene en la Conquista febril y violento período de destrucción de lo autóctono y de feroces desenfrenos, en que: "cortada fue la tierra por cuchillos invasores" Neruda (1950e, pág. 64), quedaron establecidas las bases de su régimen de explotación. Es evidente que la relación de Neruda con la Historia no es en el fondo, sino el resultado de la relación vital del poeta con el medio en que se desenvuelve su propia existencia. Él se sabe enraizado en los pueblos de América que tienen una historia que los envuelve, de la que él participa y que le confiere una identidad esencial que determina el verdadero y hondo significado de su vida y de su palabra creadora.

Lo expuesto hasta ahora, groso modo, fue apreciado en Neruda e igualmente lo estimaremos con Palomares, este poeta venezolano donde la poesía se configura en una síntesis muy personal de cierto surrealismo, mezclado con la fluidez y el vocabulario coloquial, abordando, a veces, temas históricos y narraciones heroicas; Palomares en esta obra establece; un diálogo con su contexto histórico y no puede ser de otra manera, la Historia es el lugar de encarnación de la palabra poética, debido a que sin palabra común no hay poema y sin palabra poética tampoco hay sociedad; este poeta con Santiago de León de Caracas, innova la Historia, Maggi (1982a), no solo para transformarla, sino para transformar otra imagen de ella.

En Santiago de León, se narra un acontecimiento histórico, puede ser que no se comprenda que se está escribiendo la Historia en un sentido amplio. La visión de lo histórico en el lector es invadida por la condición lúdica frente a las imágenes y voces que participan en la substanciación poética. La poesía 
va a colocar a la Historia y a sus discursos posibles en esa dimensión del lenguaje donde la palabra funciona como un metalenguaje de la Historia. La poesía regresa buscando raíces, haciendo y deshaciendo la Historia para fomentarla desde la facultad de lo imaginario, la Historia se convierte así en un objeto discursivo de otro discurso, el de la poesía: pasada al espejo de la escritura poética, "el mundo" que se demuestra de incomparables maneras, comienza a vivir independientemente y a perfilarse como una realidad de sentido, una Historia alterna capaz de producir esos sentidos.

Ramón Palomares, ha incursionado en un campo muy poco abordado por los poetas venezolanos contemporáneos: el de la Historia nacional (al igual que Neruda con Chile y su Canto General). Con Santiago León de Caracas, se detiene en momentos relevantes de la Historia de Venezuela, pero, podríamos decir que, con una actitud completamente nueva, no incurre en la exaltación patriótica (histórica), muchas veces ciega y exagerada de las epopeyas o de la Poesía histórica convencional Maggi (1982b), sino que por el contrario, sus poemas constituyen un acercamiento, sencillo y fundamental a la Historia y sus personajes, despojándolo de toda solemnidad artificiosa y aproximándolos al lector. (Los antecedentes de este tipo de poesía habría que buscarlos en el folclore: romances y cantos históricos, en los que el pueblo versó sobre personajes y episodios de la Historia, con admiración, familiaridad y humor).

En Santiago de León de Carcas se relata el tiempo en que fijaron sus pendones y levantaron sus espadas aquellos que vinieron del mar. El eje argumental de la obra es la fundación de Caracas y los hechos próximos a ella, pero más que narrar el hecho histórico, lo que pretende es hacer sentir el espíritu de los conquistadores y de los conquistados, quiénes fueron y cómo se expresaron esos hombres, sus temores, sus ambiciones, su coraje. Se trata de la violencia y la crueldad de la empresa conquistadora con todo lo que de fabulación y de insólito hubo en ella. El libro está dividido en cinco partes y 
comprende cuarenta y un poemas, en ellos vemos aparecer a Diego de Losada, Pedro Reynoso, Francisco Fajardo, y otros conquistadores, también a Guicaipuro, Tiuna, Paramaconi y otros Caciques indígenas. Las voces de uno y de otro se intercalan en los poemas. Los conquistadores narran episodios en los que han tomado parte, y en esas narraciones se vislumbra el asombro del español ante el nuevo mundo, tal y como se percibe en los cronistas de Indias. Palomares (1967a):

Que belleza la tierra cuando esa montaña sube un cuerpo blanco en sus aires y se estima su altura. Y el azul se ve limpio y es un filo quede solo lejano está bello. Apenas una línea de aurora y ya los caballeros reconocieron todo el sitio: ¡Qué templados aires! ¡Qué colinas! (pág. 125).

Está también la visión del indígena, el asombro del primer habitante de esas tierras ante la llegada del invasor, y el odio y la terrible furia ante su crueldad. En Flecheros ellos, y corredores y saltadores nosotros, los caciques del centro se acuerdan para la guerra. Palomares (1967b):

Podrida la tierra con esos fieros y terribles del mar. Achicaron los hombres volviéndolos un pasto ¡Ya no hay camino que no pasen! Llegó el día de meter los críos y las mujeres en la niebla. Todos los hombres bajarán por uno y por otro lado, por las alturas y la tierra entre los ríos sobre piedra y espuma, como puntas de lluvia y piedras, como cabellos de mujer y monte y más que hormigas bajarán. Pide a tus dioses, invasor ¡Limpia muy bien tus armas! (págs. 137-138).

Así la Historia de la fundación de Caracas no es unilateral, se trata de comprender el fenómeno de la conquista de una manera más profunda y global, desde la poesía, desde la polivalencia poética. Es evidente la expoliación, el exterminio de los indios por parte del cruel conquistador, que, a su vez, siente amor por la ciudad fundada, por las nuevas tierras conquistadas. Palomares (1967c):

Tal vez no seas la más hermosas de las Indias, $\mathrm{Ni}$ tu tesoro 
llegue a un sexto de Méjico. Más qué motivo que no fuera la muerte podría sacarnos de estas calles ¡Ah, casas sin pizca de lujo ni donaires de palacetes ni pretensiones de virreyes! Santiago, Santiago de León, semejanza nuestra! (pág. 144).

En las tres primeras partes del poemario a saber: Borburata de los Fantasmas, Flecheros ellos y corredores y saltadores nosotros y El caballero Juan Rodríguez Suárez, vamos a encontrar un elemento importante de resaltar; en todas ellas los intertítulos de los poemas van a enmarcar una situación concreta como posible "relato histórico". Entonces, podemos considerar que la Imagen Poética hace que el referente histórico estalle en múltiples sentidos. Desde la alusión a una Historia, a un pasado, a sus textos, a una épica fonológica e ideológicamente forjada desde la visión del coloniaje, se rompe sus límites. La palabra encarna a la Historia para hacerla nuevamente, fuera del canon establecido por los conquistadores de siempre, los que excluyen el discurso del otro, el que resiste al ya hoy no muy extraño invasor.

Así se abre el diálogo entre la Poesía y la Historia, pues como dice Paz, en El Arco y la Lira: "La Historia es el lugar de encarnación de la palabra poética." (1956b, pág. 143). Así el poema es la revelación de las voces del hombre para la comunicación poética, para su concreción como "epos" transformado en Imagen. Así la poesía, el poeta y el lector en poesía se adueñan del "epos" de la Historia dominante y éste es enlazado al campo de las otras visiones insólitas, desgarradas y humanas como actos de revelaciones de la metáfora y, se invoca la palabra poética a esa asociación secreta entre el hombre y lo otro, su condición de existencia relacionada, a través de múltiples lenguajes, con las imágenes que de aquello va construyendo. No debemos olvidar que, Ramón Palomares (Poeta Trujillano), al igual que Pablo Neruda, se encuentran envueltos y tal vez absorbidos por el contexto histórico de su época. Así como Neruda le cantó reflexiva y 
subversivamente al sistema de su país, así lo hace también Palomares, su poesía se encuentra íntimamente ligada a una experiencia vital.

Al igual que Neruda con Chile, Palomares experimenta vivencias que sustancian su personalidad y su rebelión contra el sistema social venezolano del momento. En Santiago de León, los versos de este poeta contienen algo así como la profesión de su fe, son la expresión de la visión que él tiene de la Historia.

\section{La Literatura y la Historia en las Instituciones Educativas.}

Las instituciones educativas están identificadas por su carácter histórico social y por su complejidad, aunque en la mayoría de las ocasiones se muestre como natural y simple; aparentemente los alumnos recurren a ellas en búsqueda de una "formación" que les permita adaptarse al sistema social que les envuelve. Pero, la escuela cumple funciones que van más allá del simple proceso de adaptación social, puesto que, su realidad implica una serie de responsabilidades que apuntan a ocuparse de: guardar a los niños, a los adolescentes al irse incrementando la escolaridad obligatoria, a la implantación de valores dominantes, y a la vigilancia disciplinadora para la subordinación y el mundo del trabajo, en otras palabras, un arduo entrenamiento para el campo laboral.

Con respecto a lo anteriormente expuesto, se puede decir que una parte de los efectos de la praxis educativa escolar está íntimamente relacionada con la complexión del sujeto, la cual concierne al establecimiento de unos juicios que le permitan al alumno creerse y juzgarse a sí mismo, acerca de los otros. Con esta orientación van a ser la escuela y sus mecanismos pedagógicos, los que construirán y mediarán esas relaciones de experiencias consigo mismo y con su otredad. Dentro de este proceso de experiencia y formación educativa la Literatura y la Historia cumplen un rol protagónico, por cuanto ambas alocuciones registran de distintas maneras, el repertorio empírico del ser 
humano; y es que la Historia no es un museo de objetos muertos, ni mucho menos puede verse como una tienda de antigüedades.

La Literatura es una alternativa para conocer la Historia de manera pura, sin la intervención de los fenómenos políticos que rigen los aspectos formales de la historia contada desde la orientación de los valores dominantes enseñados institucionalmente. La visión poética es una visión holística de la Historia que escapa a los controles de lo establecido por parámetros emanados de esos factores ideológicos dominantes de determinada sociedad; desde la época medieval podemos ver el uso de la literatura como un referente alternativo que en muchos casos contradice lo establecido situando al lector en las realidades vivenciales, mostrando al lector las caras ocultas de la Historia, tal es el caso del Carnaval Literario de Cervantes, Don Quijote de la Mancha y Lazarillo de Tormes, entre otras muchas obras de la picaresca literaria que desnudaban las realidades escondidas por lo factores dominantes de la época.

Es importante destacar que la historia abordada desde los distintos programas educativos no se contrapone al discurso literario, pero es limitada por los factores dominantes, y a su vez el discurso literario devela la cara oculta de la Historia que no se ve en el proceso educativo, sin entrar en contradicción con éste, siendo ambos discursos vertientes necesarias del conocimiento.

Finalmente, la Historia y la Literatura poseen una conexión indudable, demostrada con el análisis de los textos Canto General y Santiago de León de Caracas, donde estos escritores a partir de la Imagen Poética establecen, por un lado, un diálogo eficaz entre estos discursos, y por el otro, logran mostrarnos una nueva interpretación de la Historia, ofreciendo así esa lectura alternativa tan necesaria en los planes del sistema escolar. El discurso histórico manejado por estos poetas no responde a la "anti-historia" todo lo contrario, presentan una mirada adicional, de las múltiples que puede tener la Historia, ya que ésta, avanza en oleadas, y estas oleadas, y estas olas se 
adelantan hasta alcanzar su máximo volumen y luego retroceden para avanzar después aún más.

En atención a los aspectos anteriormente señalados, cabe preguntarse:

¿Si la Literatura y la Historia convergen entre sí, por qué no hacer uso de la Literatura para facilitar el conocimiento histórico?

¿Cómo lograr que la Literatura se convierta en una herramienta eficaz para que el estudiante se identifique con la Historia?

¿Podría decirse que la Literatura renueva la Historia?

¿Por qué si la Historia y la Literatura se alimentan la una de la otra, complementándose en su constitución con elementos propios, se les ha disminuido el valor formativo-enriquecedor que aportan en el desarrollo del estudiante?

\section{Referencias}

Acevedo, M. Arista, V. Carretero, M. Lima, L. Miralles, P. Prats, J \& Santacana, J. (2011). Enseñanza y Aprendizaje de la Historia en la Educación Básica. Teoría y Práctica Curricular de la Educación Básica. Universidad Pedagógica Nacional. México: Primera Edición. Recuperado de:

http://www.ub.edu/histodidactica/images/documentos/pdf/ensenanza aprendizaje historia educacion basica.pdf

Hernández, L. (1998). La palabra en el Tiempo, el Tiempo en la palabra. Caracas: Dirección General de Cultura y Extensión, Universidad de los Andes.

Maggi, M. (1982a,b). La Poesía de Ramón Palomares y la Imaginación Americana. "La poesía como hecho vital". Caracas: Centro de Estudios Latinoamericanos "Rómulo Gallegos".

Neruda, P. (1950a,b,c,d,e). Canto General. Barcelona: Editorial Seix Barral, 
S.A.

Palomares, R. (1967a,b,c). Santiago de León de Caracas. Caracas:

Ediciones de la Comisión del Cuatricentenario de Caracas. Monte Ávila Editores.

Paz, O. (1956a,b). El Arco y La Lira. México: Fondo de Cultura Económica.

Siwka, C. (1982a,b). Historia, Biografía y Literatura. Caracas: Dirección de Cultura. Universidad Central de Venezuela.

Valverde, Y. (2014a,b,c,d). Lectura y Escritura con sentido y significado, como estrategia de pedagógica en la formación de maestros. Revista Fedumar Pedagogía y Educación, 1(1), págs. 71-104. Recuperado de:

http://www.actiweb.es/educadora andrea reyes/archivo6.pdf 


\section{Rina Desireé Colina Matos}

e-mail: desicolina1203@gmail.com

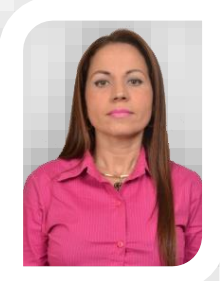

Nacida en Venezuela. Licenciada en Educación, mención: Castellano y Literatura (Universidad de Los Andes, Núcleo Universitario "Rafael Rangel", TrujilloVenezuela). Distinción Cum Laude. Magíster en Gerencia de la Educación. (Universidad de Los Andes, Núcleo Universitario "Rafael Rangel". Trujillo-Venezuela.). Doctorante en Educación, (Universidad Experimental "Rafael María Baralt", Maracaibo-Venezuela). Docente Titular del Ministerio del Poder Popular Para La Educación - Venezuela. Su trayectoria profesional abarca el ser Docente de Aula, Coordinadora Pedagógica; Coordinadora de Bienestar Estudiantil, Subdirectora Administrativa, Directora de la Unidad Educativa: "Barrio Nuevo" Valera, donde actualmente se desempeña como Coordinadora Institucional. En el ámbito universitario fue Profesora Contratada en el Instituto Tecnológico "María Briceño Iragorry"; en la Universidad de las Fuerzas Armadas (UNEFA) Núcleo Trujillo; Profesora Invitada en el Departamento de Ciencias Pedagógicas de la Universidad de Los Andes, Núcleo "Rafael Rangel”, Trujillo, Edo. Trujillo. Tiene como áreas de trabajo e investigación: Lengua y Literatura y Gerencia Educativa.

El contenido de este manuscrito se difunde bajo una Licencia de Creative Commons ReconocimientoNoComercial-Compartirlgual 4.0 Internacional 